\title{
ESR Dating of Barite in Sea-Floor Hydrothermal Sulfide Deposits in the Okinawa Trough
}

\author{
Taisei Fujiwara, Shin Toyoda, Ai Uchida, Jun-ichiro Ishibashi, \\ Shun'ichi Nakai, and Asako Takamasa
}

\begin{abstract}
ESR (electron spin resonance) ages were determined for barite crystals extracted from hydrothermal sulfide deposits taken at Daiyon-Yonaguni Knoll field, Hatoma Knoll field, Iheya North Knoll field, Hakurei Site of Izena Hole field, Yoron Hole field of the Okinawa Trough. The ages range from 4.1 to 16,000 years, being consistent with detection of ${ }^{228} \mathrm{Ra}$ in younger samples and radioactive equilibrium/disequilibrium between radium and daughter nuclei. The variation of the ages within each sample is mostly within the statistical error range. The relative order of the ages is consistent with the result of ${ }^{226} \mathrm{Ra}^{2}{ }^{210} \mathrm{~Pb}$ method, but the determining absolute ages is still an issue. The order of ages of the 5 hydrothermal fields would be arranged, from young to old as follows; Yoron Hole field, Daiyon-Yonaguni Knoll field, Hatoma Knoll field, being nearly equal to Iheya North Knoll field.
\end{abstract}

Keywords

Barite $\bullet$ Dating $•$ Electron spin resonance $\bullet$ Hydrothermal activities

\subsection{Introduction}

There have been many scientific efforts devoted for studies on active sea-floor hydrothermal fields found in Okinawa Trough (Ishibashi et al. Chap. 23). The evolution of these hydrothermal fields is one of the important issues. Dating methods have been employed for hydrothermal sulfide deposits, such as the U-Th disequilibrium method (e.g. You and Bickle 1998) applicable for the age range more than several thousand years, and ${ }^{226} \mathrm{Ra}-{ }^{210} \mathrm{~Pb}$ and ${ }^{228} \mathrm{Ra}^{228} \mathrm{Th}$ method (e.g. Noguchi et al. 2011) for the

T. Fujiwara $\bullet$ S. Toyoda $(\bowtie) \bullet$ A. Uchida

Okayama University of Science, Okayama, Japan

e-mail: toyoda@dap.ous.ac.jp

J.-i. Ishibashi

Kyusyu University, Fukuoka, Japan

S. Nakai

University of Tokyo, Tokyo, Japan

A. Takamasa

National Institute of Radiological Sciences, Chiba, Japan range less than 150 years. The age range of several hundred years is essential to estimate the life time of hydrothermal activities. However, dating methods for the age range are lacking.

Okumura et al. (2010) made the first practical application of ESR dating technique to a sample of seafloor hydrothermal barite to obtain ages of 300 and 3,620 years, while Kasuya et al. (1991) first pointed out that barite can be used for ESR dating. Toyoda et al. (2011) determined the optimum ESR condition while Sato et al. (2011) confirmed that the signal is thermally stable enough for an age range of several thousand years.

Seafloor massive sulfide deposits are composed of sulfide minerals such as pyrite, sphalerite, chalcopyrite and galena, and also include sulfate minerals such as anhydrite and barite. The sulfate minerals precipitate by mixing of hydrothermal fluid and seawater, while the sulfide minerals precipitate from the hydrothermal fluid mainly by cooling (Hannington et al. 1995). It is generally considered that a combination and/or switch of these two modes of hydrothermal precipitation lead to growth of sulfide structures such as a chimney and mound and that of large hydrothermal 
deposits (e.g. Tivey 2007). Takamasa et al. (2013) determined ESR ages for barite in sulfide deposits in the South Mariana Trough hydrothermal field, and concluded that the ages are consistent with U-Th ages. In this study, the ages of various hydrothermal sulfides in the Okinawa Trough are determined by ESR dating.

\subsection{Material and Methods}

The sulfide deposit samples were obtained in the 6 research cruises; NT01-05, NT02-07, YK04-05, NT11-20, NT12-06, and NT12-10 operated by the Japan Agency for MarineEarth Science and Technology (JAMSTEC) from DaiyonYonaguni Knoll field, Hatoma Knoll field, Iheya North Knoll field, Hakurei field of Izena Hole field, Yoron Hole field of the Okinawa Trough (Figs. 29.1 and 29.2, and Table 29.1). After blocks of sulfide sample were cut into pieces (Fig. 29.3), approximately $2.0 \mathrm{~g}$ of the pieces was crushed. The samples were soaked in $12 \mathrm{M}$ hydrochloric acid for approximately $24 \mathrm{~h}$. Then, $13 \mathrm{M}$ nitric acid was added. Finally, after rinsing in distilled water, the sample was filtered and dried. Mineral grains other than barite were removed by handpicking. The purified mineral grains were determined by an X-ray diffraction and confirmed that the grains are pure barite.

The barite grains extracted from each sample were separated into 100-250 $\mu \mathrm{m}$ aliquots for gamma ray irradiation up to about $10 \mathrm{kGy}$ with a dose rate of $404.4 \mathrm{~Gy} / \mathrm{h}$ made at Takasaki Advanced Radiation Research Institute, Japan Atomic Energy Agency (JAEA). The sample aliquots were measured at room temperature with an ESR spectrometer (JES-PX2300) with a microwave power of $1 \mathrm{~mW}$, and the magnetic field modulation amplitude of $0.1 \mathrm{mT}$ as indicated by Toyoda et al. (2011) to be the best measurement conditions. The equivalent natural radiation doses were obtained by extrapolating the obtained dose response curve of the $\mathrm{SO}_{3}{ }^{-}$signal to the ordinate intercept.

The bulk radium $\left({ }^{226} \mathrm{Ra}\right.$ and $\left.{ }^{228} \mathrm{Ra}\right)$ concentrations were measured by the low background pure Ge gamma ray spectrometer. Assuming that $\mathrm{Ra}$ is populated only in barite as confirmed by Okumura et al. (2010), the internal and external dose rates of alpha, beta and gamma rays given to the barite minerals were calculated (Toyoda et al. 2014). The alpha effectiveness of 0.043 was adopted (Toyoda et al. 2012). Corrections were made for water content, beta ray attenuation for grain sizes (a plane with $20 \mu \mathrm{m}$ in thickness as confirmed by thin section). In the present paper, a new formula is proposed to obtain the ages which takes into account the decays of ${ }^{226} \mathrm{Ra}$ (a half life of 1,600 years) and ${ }^{228} \mathrm{Ra}$ (a half life of 5.75 years) with disequilibrated daughter nuclei as the following.

\subsection{The Dose Rate Conversion Factors and the Decay Corrections for ${ }^{226} \mathrm{Ra}$ and ${ }^{228} \mathrm{Ra}$}

It is the most important feature of hydrothermal barite in the aspect of dose rate estimation that the only source of the radiation is internal radium (Okumura et al. 2010; Toyoda et al. 2014). The dose rate was calculated from the concentrations of radium and its daughter nuclei as the following.

The newest dose rate conversion factors, which are to be multiplied to the concentrations of $\mathrm{U}, \mathrm{Th}, \mathrm{K}$ to obtain dose rate, were reported by Guérin et al. (2011) for U and Th in radioactive equilibrium and for $\mathrm{K}$ together with the contributions of each nucleus in the decay chains. Toyoda et al. (2014) obtained the dose rate conversion factors from their table for ${ }^{226} \mathrm{Ra}$ only in the case of radioactive equilibrium. By summing up the energy contributions of the nuclei in the chains listed in Guérin et al. (2011), the dose rate conversion factors for ${ }^{226} \mathrm{Ra}$ and ${ }^{228} \mathrm{Ra}$ were calculated so that the dose rate can be obtained in the case of radioactive disequilibrium as shown in Table 29.2.

When the dose rate varies with time in the past, the equivalent dose, $D_{\mathrm{E}}$, obtained by the ESR measurements is expressed by the integration of a time dependent dose rate, $\mathrm{D}$ $(t)$, as the following,

$$
D_{E}=\int_{0}^{T} D(t) d t
$$

As the source of the dose is Ra which decays with time, the decay has to be taken into account for the does rate, $D(t)$. For the decay of ${ }^{226} \mathrm{Ra}$, Toyoda et al. (2014) obtained a formula as

$$
T=\frac{1}{\lambda} \ln \left(\lambda \frac{D_{E}}{D}+1\right)
$$

This formula is valid for the samples with ages over 200 years where the daughter nucleus with second longest half life $\left({ }^{210} \mathrm{~Pb}, 22.3\right.$ years) in the decay series is equilibrated. However, for the younger samples, the radioactive disequilibrium and contributions from the decay series starting from ${ }^{228} \mathrm{Ra}$ have to be considered.

When the number of nuclei of ${ }^{226} \mathrm{Ra}$ or ${ }^{228} \mathrm{Ra}$ is $\mathrm{N}_{1}$, and that of the daughter nuclei with second longest life $\left({ }^{210} \mathrm{~Pb}\right.$ or ${ }^{228} \mathrm{Th}$ ) is $\mathrm{N}_{2}$, those are expressed as,

$$
\begin{gathered}
N_{1}=N_{10} e^{-\lambda_{1} t} \\
N_{2}=\frac{\lambda_{1}}{\lambda_{2}-\lambda_{1}} N_{10}\left(e^{-\lambda_{1} t}-e^{-\lambda_{2} t}\right)
\end{gathered}
$$




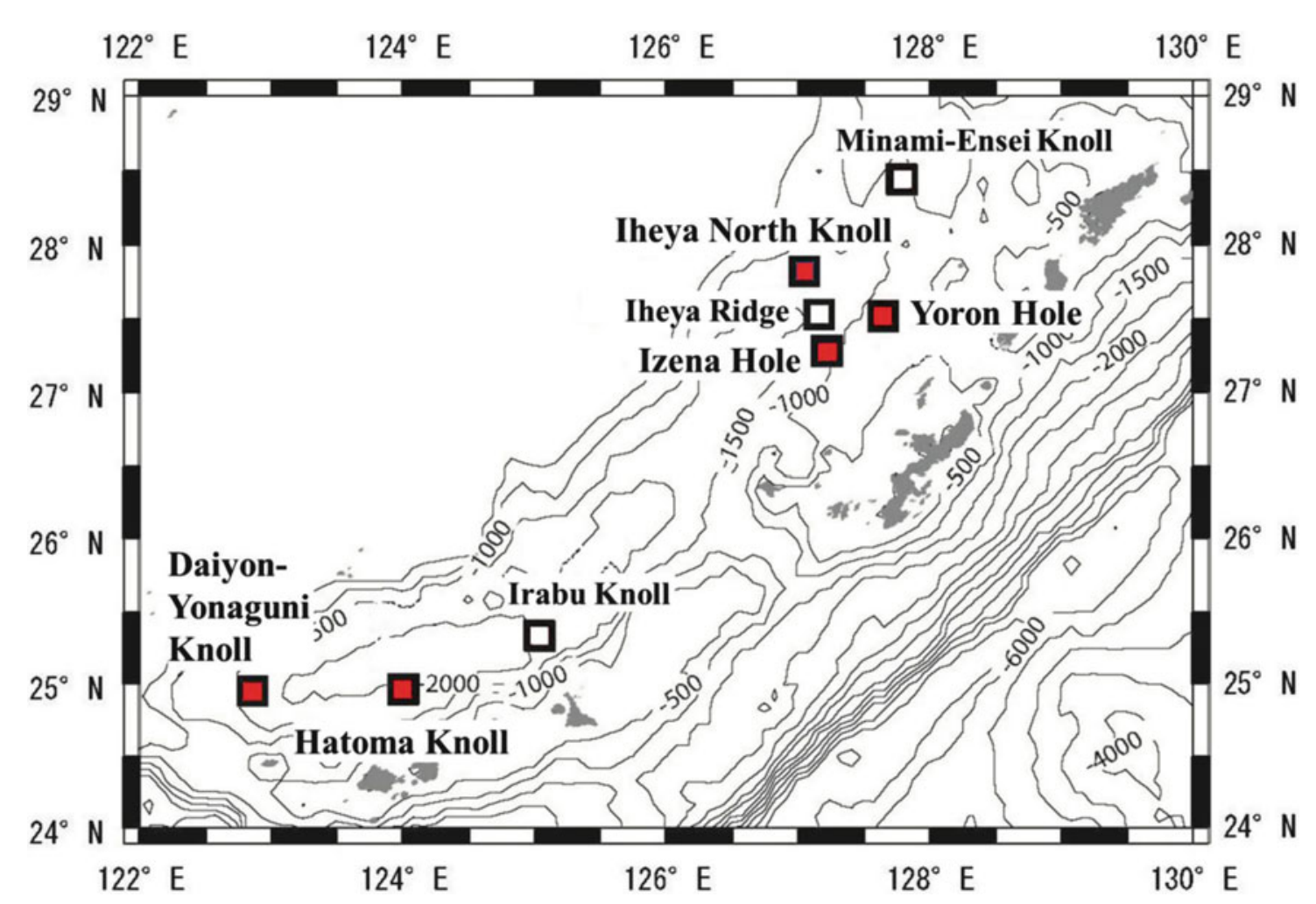

Fig. 29.1 A bathymetric map of the known hydrothermal fields and sampling fields in the Okinawa Trough. Red triangles indicate the sampling fields; Daiyon-Yonaguni Knoll field, Hatoma Knoll field, Iheya North Knoll field, Hakurei field of Izena Hole field, Yoron Hole field

where $\mathrm{N}_{10}$ is the initial number of parent nuclei, $\lambda_{1}$ and $\lambda_{2}$ are the decay constant of the parent and the daughter nuclei, respectively, and it is assumed that initially no daughter nuclei are present. We only know the number of nuclei at present, $\mathrm{N}_{1 \mathrm{p}}$, expressed as,

$$
N_{1 p}=N_{10} e^{-\lambda_{1} T}
$$

where $\mathrm{T}$ is the age of the sample. Therefore, Eqs. (29.3) and (29.4) are written as,

$$
\begin{gathered}
N_{1}=N_{1 p} e^{\lambda_{1}(T-t)} \\
N_{2}=\frac{\lambda_{1}}{\lambda_{2}-\lambda_{1}} N_{1 p} e^{\lambda_{1} T}\left(e^{-\lambda_{1} t}-e^{-\lambda_{2} t}\right)
\end{gathered}
$$

respectively.

The dose rate, $\mathrm{D}(\mathrm{t})$, given by the parent and daughter nuclei is written as,

$$
D(t)=Q_{1} \lambda_{1} N_{1}(t)+Q_{2} \lambda_{2} N_{2}(t)
$$

where $\mathrm{Q}_{1}$ and $\mathrm{Q}_{2}$ are the dose rate conversion factors for the nuclei from the parent to the one just before the daughter with the second longest life time in the decay series, and for those from that daughter and after, respectively. Please note that a conversion factor is given per unit activity, $\lambda N$. From Eqs. (29.5)-(29.7) is written as,

$$
D(t)=\lambda_{1} N_{1 p} e^{\lambda_{1} T}\left\{e^{-\lambda_{1} t}\left(Q_{1}+Q_{2} \frac{\lambda_{2}}{\lambda_{2}-\lambda_{1}}\right)-Q_{2} e^{-\lambda_{2} t}\right\}
$$

The $\mathrm{D}_{\mathrm{E}}$ is given by integrating the dose rate as the following,

$$
\begin{aligned}
& D_{E}=\int_{0}^{T} D(t) d t \\
& =\lambda_{1} N_{1 p} e^{\lambda_{1} T}\left\{\frac{1}{\lambda_{1}}\left(Q_{1}+Q_{2} \frac{\lambda_{2}}{\lambda_{2}-\lambda_{1}}\right)\left(1-e^{-\lambda_{1} T}\right)-\frac{Q_{2}}{\lambda_{2}}\left(1-e^{-\lambda_{2} T}\right)\right\}
\end{aligned}
$$

For the present case, two decay series have to be taken into account, one starting from ${ }^{226} \mathrm{Ra}$ (half life: 1,600 years) where the daughter nucleus with the second longest life time is ${ }^{210} \mathrm{~Pb}\left(22.3\right.$ years), and the other from ${ }^{228} \mathrm{Ra}(5.75$ years) where the daughter is ${ }^{228} \mathrm{Th}$ (1.91 years). In the present work, the dose rates from both series are summed and $\mathrm{T}$ is obtained by Eq. (29.9) where the present radium activities $\left(\lambda_{1} \mathrm{~N}_{1}\right)$ were used. 
a Daiyon-Yonaguni Knoll hydrothermal field

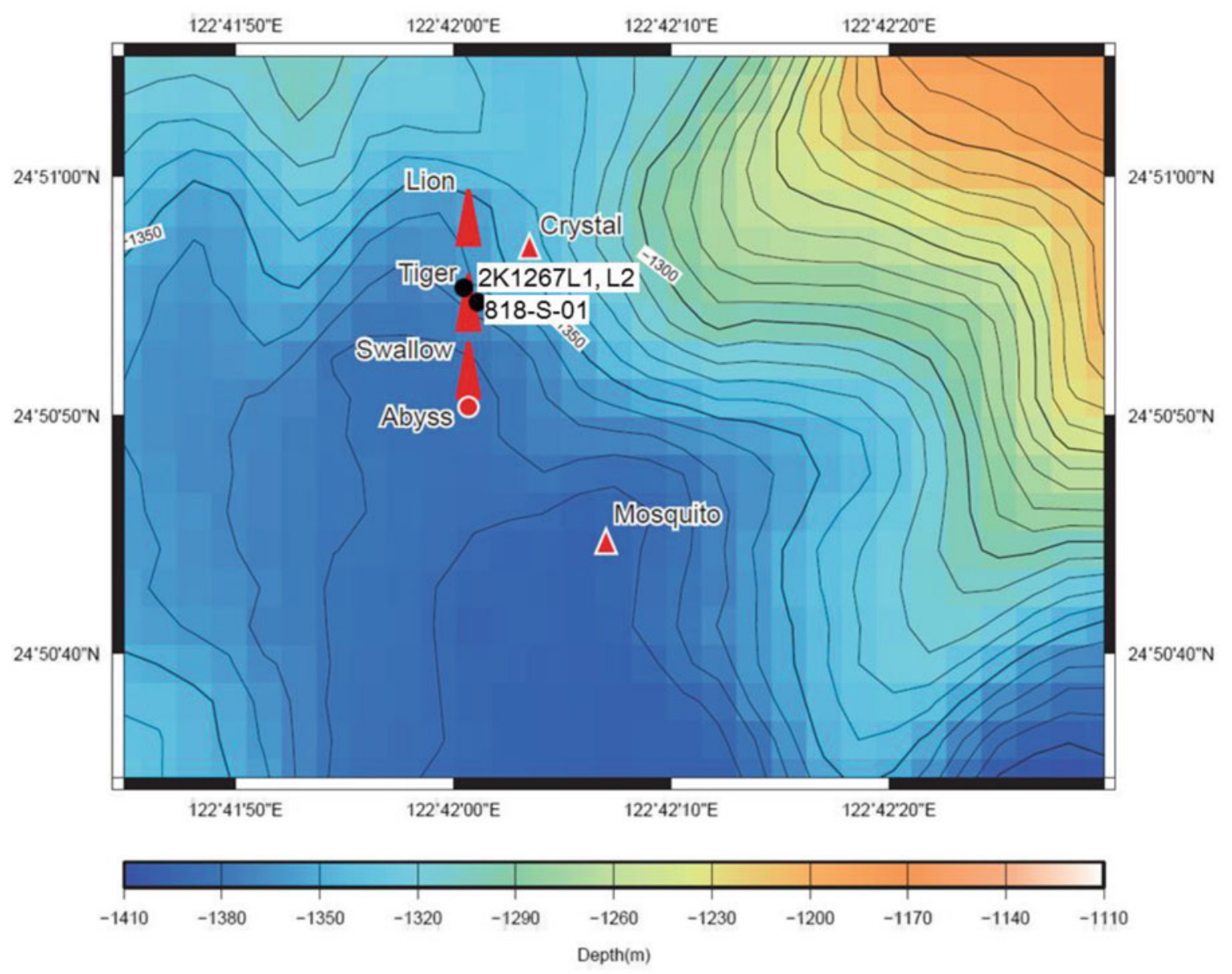

Highest temperature fluid vent

\ High temperature fluid vent $\left(>200^{\circ} \mathrm{C}\right)$

- Visible fluid flow vent

- Sampling point

Fig. 29.2 Sampling location at the five hydrothermal fields in the Okinawa Trough. (a) Daiyon-Yonaguni Knoll field, (b) Hatoma Knoll field, (c) Iheya North Knoll field, (d) Hakurei field of Izena Hole field, (e) Yoron Hole field 
b

\section{Hatoma Knoll hydrothermal field}
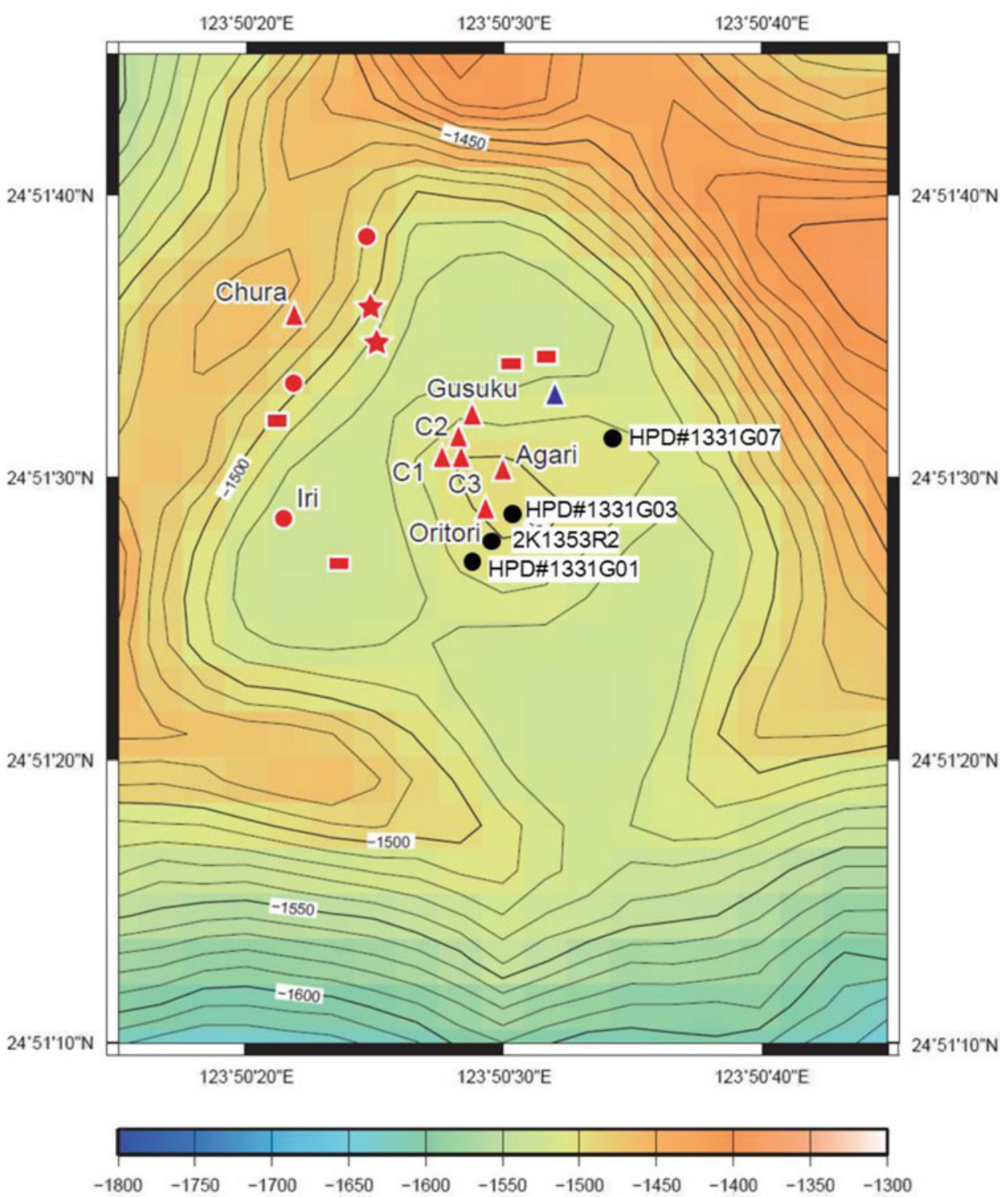

Fig. 29.2 (continued)

A High temperature fluid vent $\left(>200^{\circ} \mathrm{C}\right)$

- Visible fluid flow vent

- Microbial mat / Animal colony
Bubble vent

$\Delta$ Inactive chimney

- Sampling point 
c Iheya North Knoll hydrothermal field

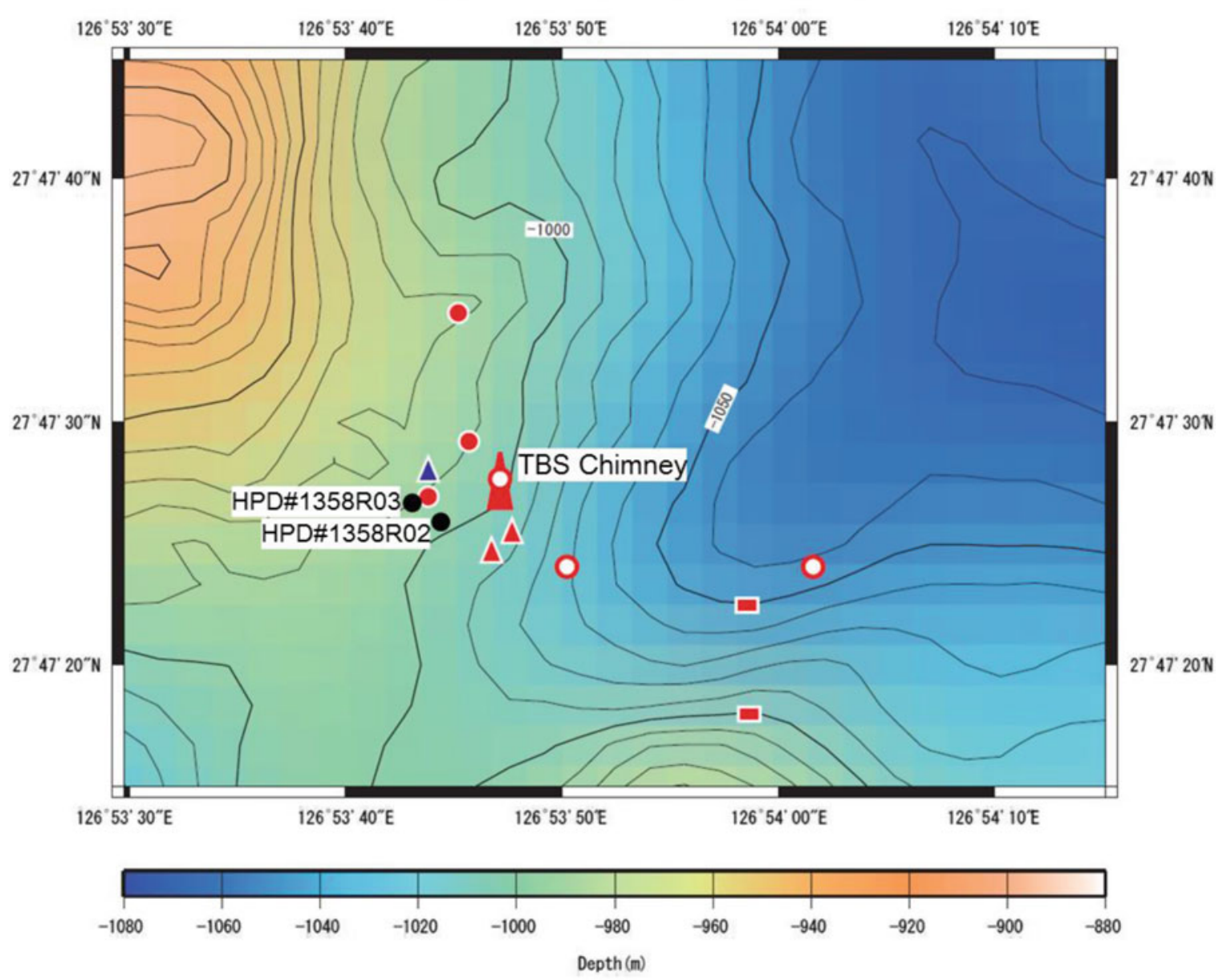

Highest temperature fluid vent

\ High temperature fluid vent $\left(>200^{\circ} \mathrm{C}\right)$ o IODP site

- Visible fluid flow vent

$\Delta$ Inactive chimney

- Microbial mat / Animal colony

- Sampling point

Fig. 29.2 (continued) 


\section{d}

Izena Hole Hakurei hydrothermal field
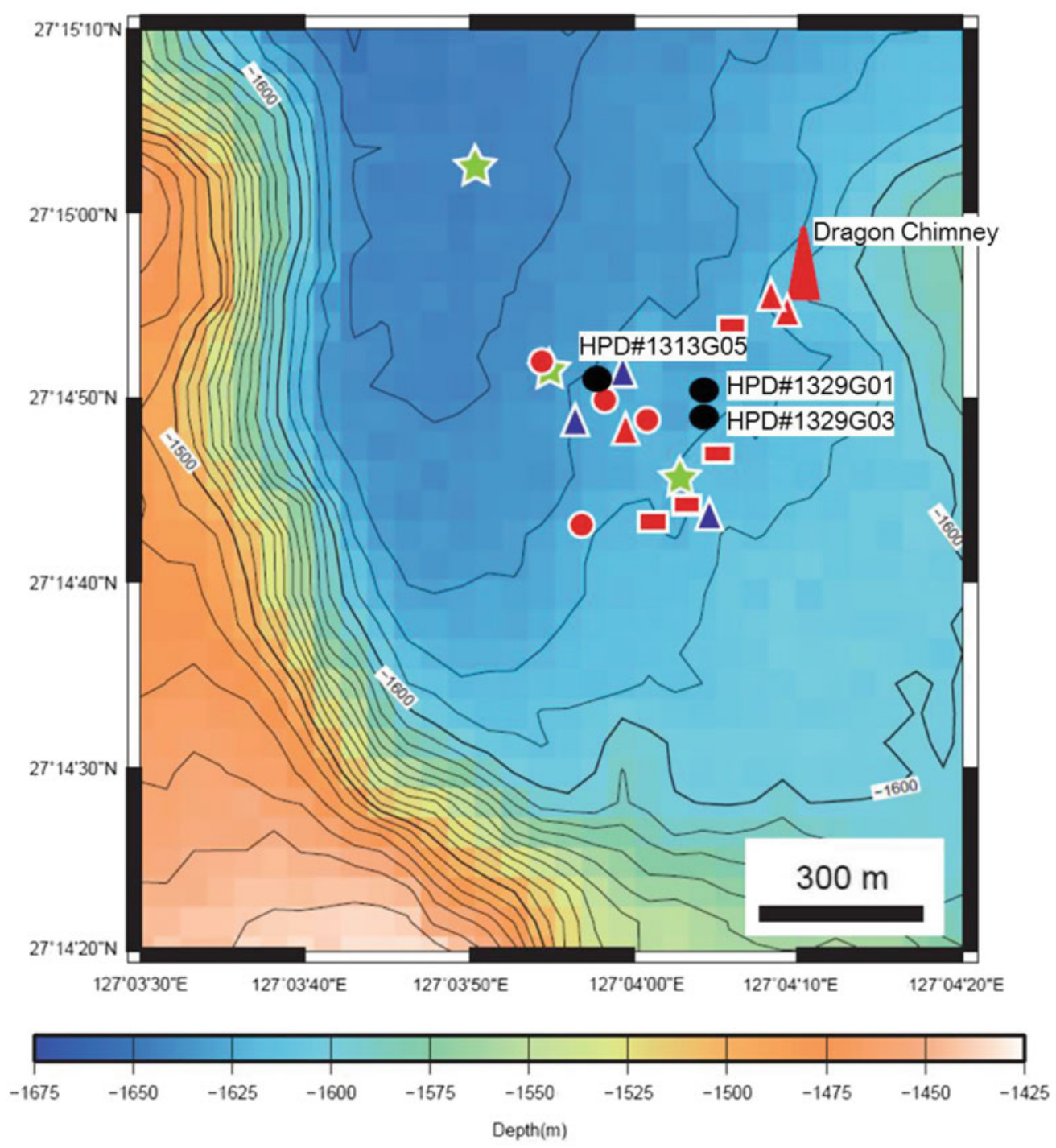

Highest temperature fluid vent

A High temperature fluid vent $\left(>200^{\circ} \mathrm{C}\right)$

Sulfur crust

- Visible fluid flow vent

$\Delta \quad$ Inactive chimney

- Microbial mat / Animal colony

Sampling point

Fig. 29.2 (continued) 
e Yoron Hole hydrothermal field

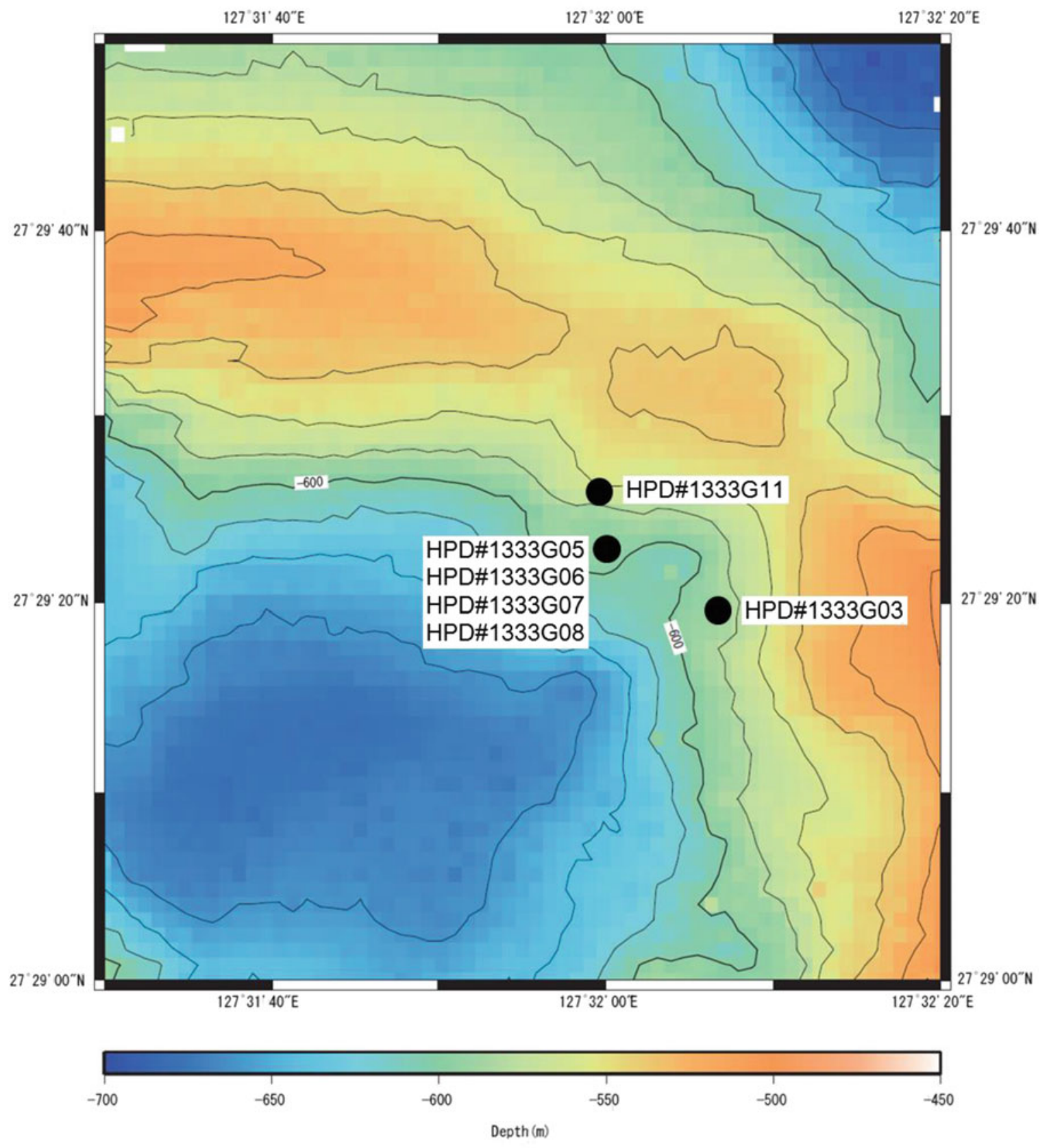

Sampling point

Fig. 29.2 (continued) 
Table 29.1 List of samples analyzed in the present study

\begin{tabular}{|c|c|c|c|c|c|c|}
\hline \multirow[b]{2}{*}{ Sample No. } & \multicolumn{2}{|c|}{ Sampling position } & \multirow[b]{2}{*}{ Depth (m) } & \multirow{2}{*}{$\begin{array}{l}\text { Sampling } \\
\text { Date }\end{array}$} & \multirow{2}{*}{$\begin{array}{l}\text { Sampling } \\
\text { Tool }\end{array}$} & \multirow[b]{2}{*}{ Description } \\
\hline & Latitude $(\mathrm{N})$ & Longitude (E) & & & & \\
\hline \multicolumn{7}{|c|}{ Yonaguni Knoll field-Daiyon } \\
\hline 818-S-01 & $24^{\circ} 50.893^{\prime}$ & $122^{\circ} 42.020^{\prime}$ & 1,363 & $5 / 28 / 2004$ & SHINKAI6500 & Active chimney \\
\hline 2K1267L1 & $24^{\circ} 50.934^{\prime}$ & $122^{\circ} 42.012^{\prime}$ & 1,366 & $5 / 16 / 2001$ & SHINKAI2000 & Active chimney \\
\hline 2K1267L2 & $24^{\circ} 50.934^{\prime}$ & $122^{\circ} 42.012^{\prime}$ & 1,366 & $5 / 16 / 2001$ & SHINKAI2000 & Active chimney \\
\hline \multicolumn{7}{|l|}{ Hatoma Knoll field } \\
\hline HPD\#1331G01 & $24^{\circ} 51.450^{\prime}$ & $123^{\circ} 50.478^{\prime}$ & 1,499 & $10 / 8 / 2011$ & Hyper Dolphyn & Inactive chimney \\
\hline HPD\#1331G03 & $24^{\circ} 51.477^{\prime}$ & $123^{\circ} 50.508^{\prime}$ & 1,477 & $10 / 8 / 2011$ & Hyper Dolphyn & Sulfide mound \\
\hline HPD\#1331G07 & $24^{\circ} 51.520^{\prime}$ & $123^{\circ} 50.559^{\prime}$ & 1,490 & $10 / 8 / 2011$ & Hyper Dolphyn & Active chimney \\
\hline 2K1353R2 & $24^{\circ} 51.455^{\prime}$ & $123^{\circ} 50.477^{\prime}$ & 1,488 & $5 / 28 / 2002$ & SHINKAI2000 & Active chimney \\
\hline \multicolumn{7}{|c|}{ Iheya North Knoll field } \\
\hline HD\#1358R2 & $27^{\circ} 47.438^{\prime}$ & $126^{\circ} 53.736^{\prime}$ & 990 & $3 / 21 / 2012$ & Hyper Dolphyn & Sulfide mound \\
\hline HD\#1358R3 & $27^{\circ} 47.460^{\prime}$ & $126^{\circ} 53.730^{\prime}$ & 982 & $3 / 21 / 2012$ & Hyper Dolphyn & Inactive chimney \\
\hline \multicolumn{7}{|l|}{ Izena Hole field } \\
\hline HPD\#1313G05 & $27^{\circ} 14.856^{\prime}$ & $127^{\circ} 03.962^{\prime}$ & 1,613 & $8 / 22 / 2011$ & Hyper Dolphyn & Active chimney \\
\hline HPD\#1329G01 & $27^{\circ} 14.838^{\prime}$ & $127^{\circ} 04.093^{\prime}$ & 1,620 & $10 / 5 / 2011$ & Hyper Dolphyn & Inactive chimney \\
\hline HPD\#1329G03 & $27^{\circ} 14.815^{\prime}$ & $127^{\circ} 03.093^{\prime}$ & 1,617 & $10 / 5 / 2011$ & Hyper Dolphyn & Inactive chimney \\
\hline \multicolumn{7}{|l|}{ Yoron Hole field } \\
\hline HPD\#1333G03 & $27^{\circ} 29.328^{\prime}$ & $127^{\circ} 32.124^{\prime}$ & 580 & $10 / 10 / 2011$ & Hyper Dolphyn & Active chimney \\
\hline HPD\#1333G05 & $27^{\circ} 29.382^{\prime}$ & $127^{\circ} 32.004^{\prime}$ & 591 & $10 / 10 / 2011$ & Hyper Dolphyn & Active chimney \\
\hline HPD\#1333G06 & $27^{\circ} 29.382^{\prime}$ & $127^{\circ} 32.004^{\prime}$ & 591 & $10 / 10 / 2011$ & Hyper Dolphyn & Active chimney \\
\hline HPD\#1333G07 & $27^{\circ} 29.382^{\prime}$ & $127^{\circ} 32.004^{\prime}$ & 591 & $10 / 10 / 2011$ & Hyper Dolphyn & Active chimney \\
\hline HPD\#1333G08 & $27^{\circ} 29.382^{\prime}$ & $127^{\circ} 32.004^{\prime}$ & 591 & $10 / 10 / 2011$ & Hyper Dolphyn & Active chimney \\
\hline HPD\#1333G11 & $27^{\circ} 29.424^{\prime}$ & $127^{\circ} 31.998^{\prime}$ & 566 & $10 / 10 / 2011$ & Hyper Dolphyn & Active chimney \\
\hline
\end{tabular}

\subsection{Results and Discussions}

A typical ESR spectrum is shown in Fig. 29.4. The principal $\mathrm{g}$ factors are calculated from this powder spectrum to be $1.9995,2.0023$, and 2.0031, being consistent with the $\mathrm{g}$ factors for $\mathrm{SO}_{3}{ }^{-}$radical obtained by Krystec (1980), which are 1.9995, 2.0023, and 2.0032. The peak-to-peak height of the spectrum (Fig. 29.4) was used as the signal intensity. An example of dose response of the signal intensity is shown in Fig. 29.5. Extrapolating the dose response to the zero ordinate, being fitted by a saturating exponential curve, the equivalent doses are obtained as shown in Table 29.3.

The ${ }^{226} \mathrm{Ra}$ and ${ }^{228} \mathrm{Ra}$ concentrations were measured by a low background pure germanium gamma ray spectrometer for bulk samples as shown in Table 29.3. The ${ }^{226} \mathrm{Ra}$ concentrations were obtained from the peak counts for ${ }^{214} \mathrm{Bi}(609,1,120,1,765 \mathrm{keV})$ and for ${ }^{214} \mathrm{~Pb}(295$ and $352 \mathrm{keV}$ ) in comparison with a standard uranite sample with radioactive equilibrium with known uranium concentration. The ${ }^{228} \mathrm{Ra}$ concentrations were from the peak counts for ${ }^{228} \mathrm{Ac}(338,911,969 \mathrm{keV})$ (Yonezawa et al. 2002). The ages of the samples were determined using the Eq. (29.6) as shown in Table 29.3.

The ages ranged from 4.1 to 16,000 years while the ages of pieces from a sample varies more than estimated analytical errors (Table 29.3). As discussed by Toyoda et al. (2014), microscopic observation revealed that sulfide minerals with various size and various occurrence fill the spaces among barite crystals, suggesting repeated stages of mineralization, which starts with sulfate precipitation and followed by sulfide precipitation. Thus the samples would consist of minerals in various ages. It would be more probable that the determined ages are somewhat "averaged" within the portion of the sample, implying that the variation in ages corresponds to the ratio of the younger to older crystals. Therefore, when the ages vary within a sample portion, it would mean that repeated hydrothermal activities have formed the sample at the time of around those ages. If this is the case, the oldest age would correspond to the youngest limit of the oldest activity.

The determined ESR ages are young up to 56 years for those samples in which ${ }^{228} \mathrm{Ra}$ is detected. It is consistent that younger samples contain ${ }^{228} \mathrm{Ra}$ with a short half life of 5.75 
Fig. 29.3 Overview of sulfide samples and analyzed parts in each sulfide
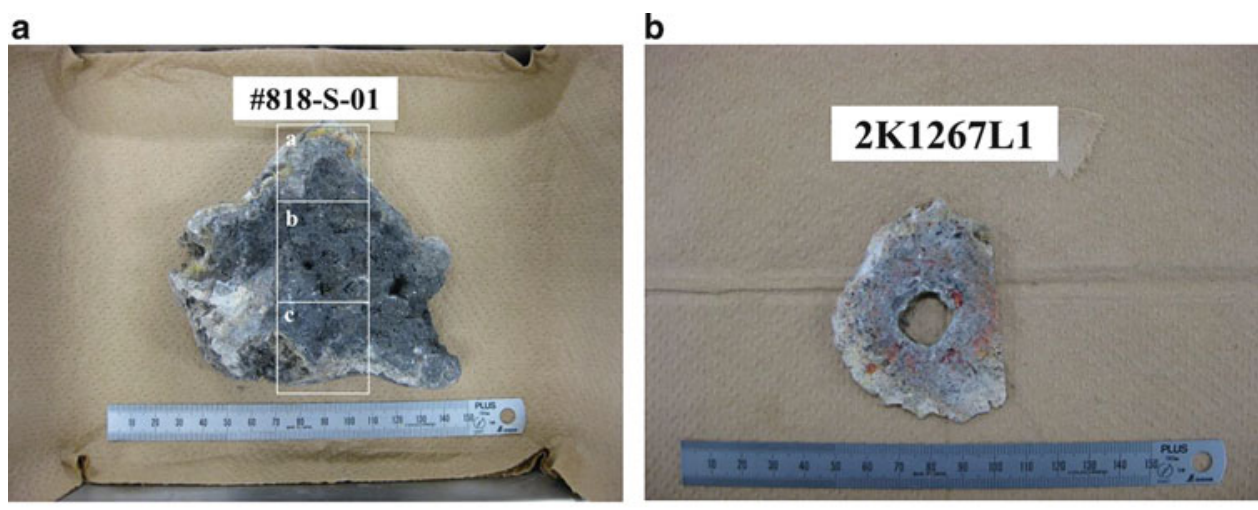

c

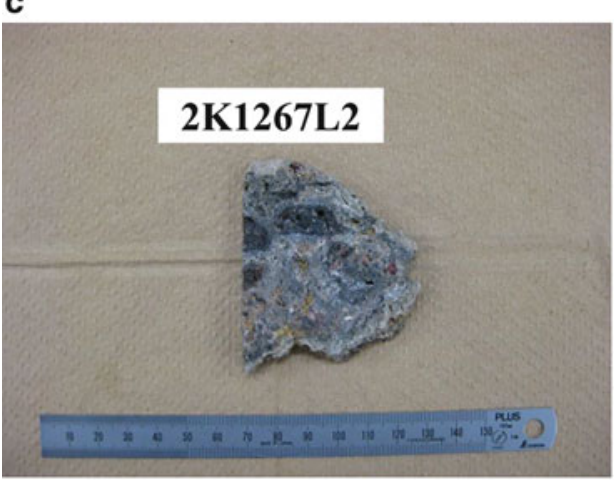

d

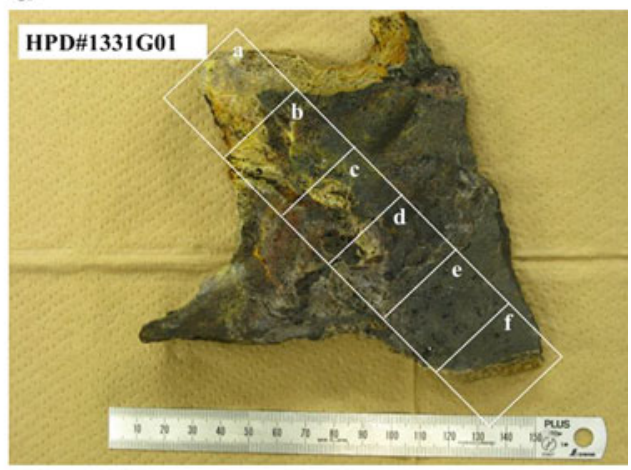

e

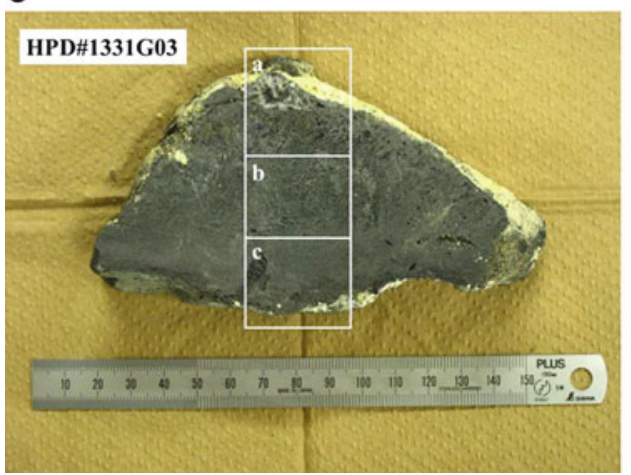

f

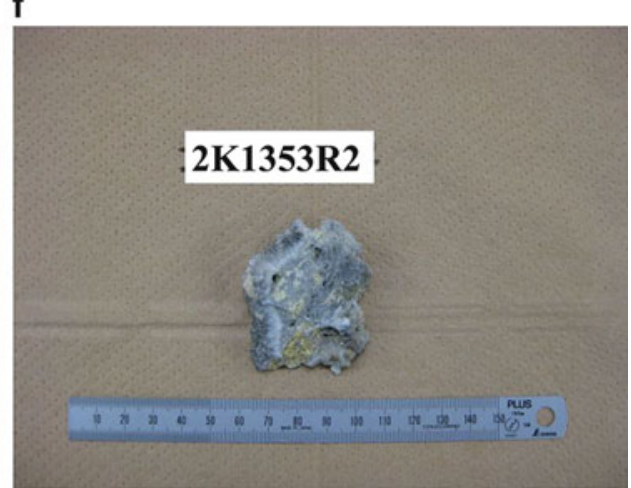




\section{g}

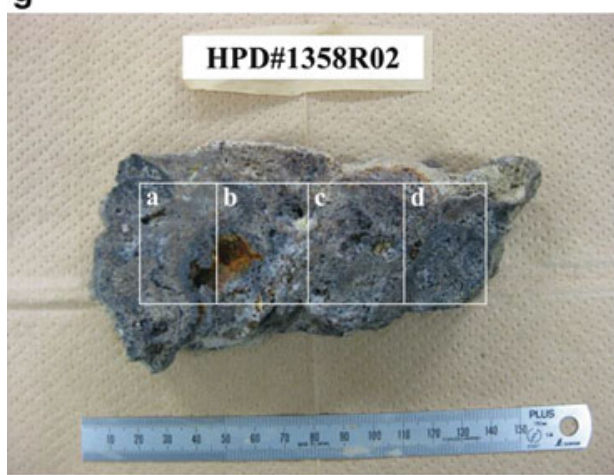

i

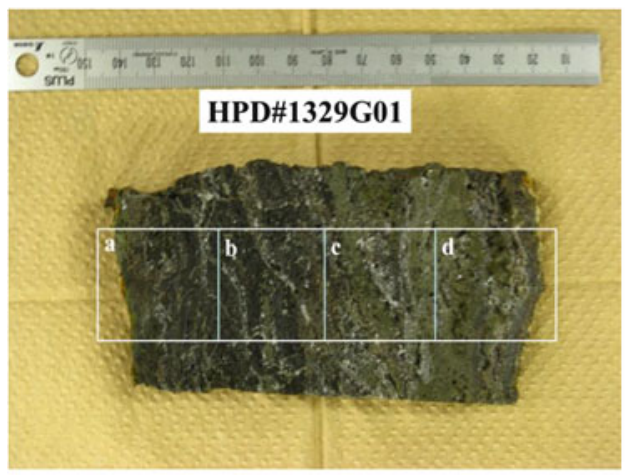

k

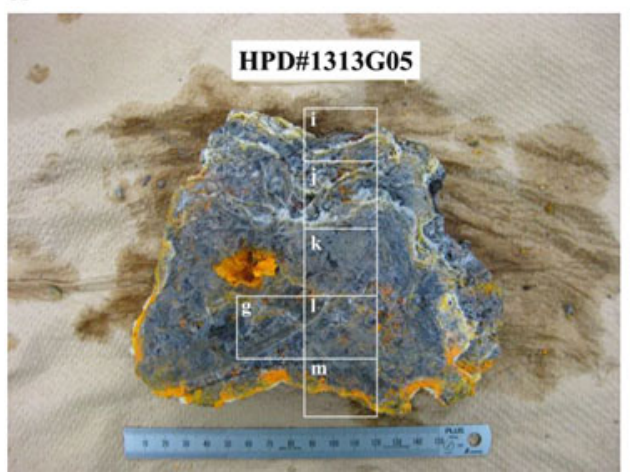

h

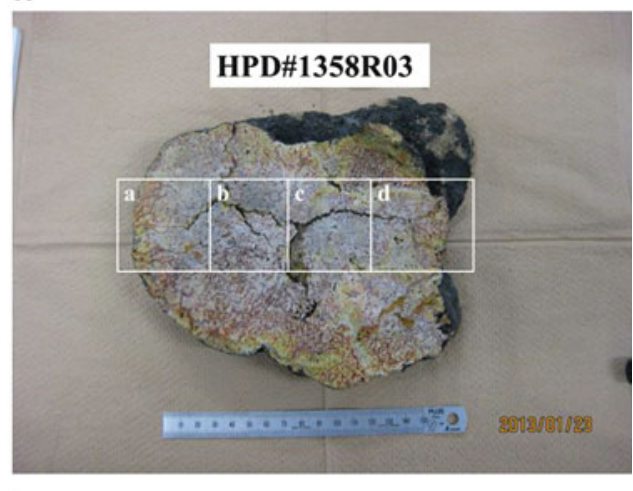

j

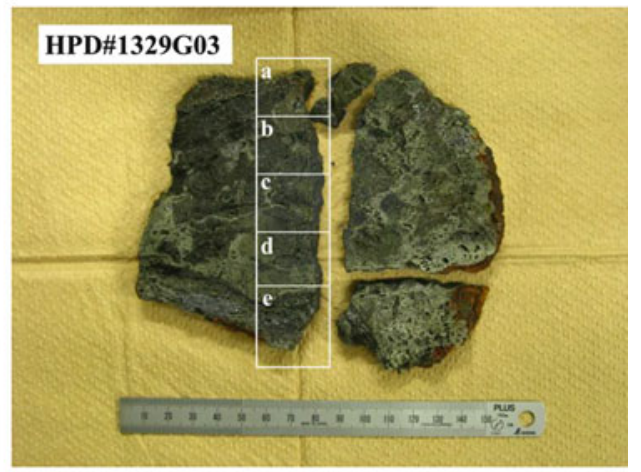

I

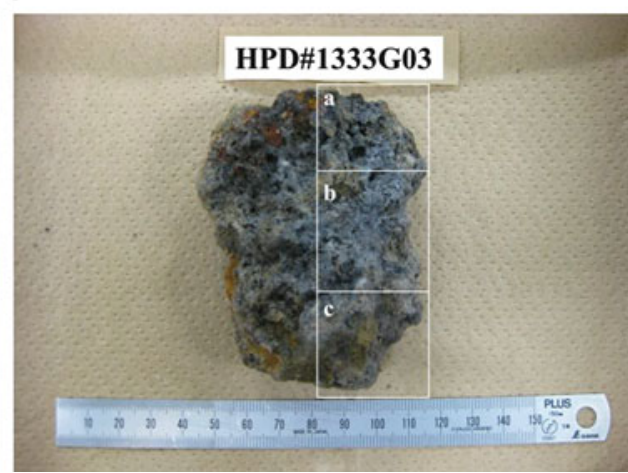

Fig. 29.3 (continued) 

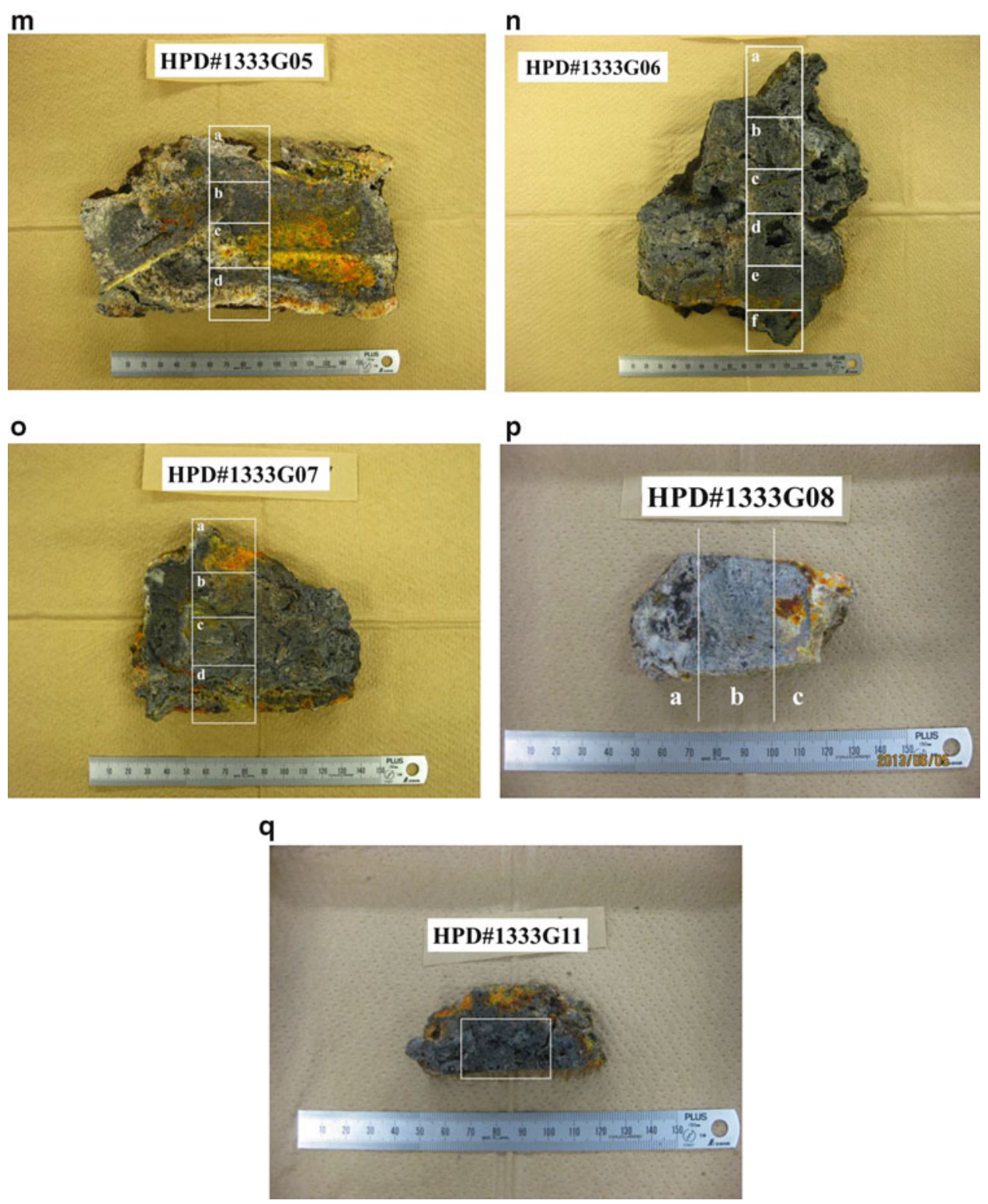

Fig. 29.3 (continued)

years. It is also reasonable that the all ESR ages for sulfide samples of active vent site are younger than those for sulfide samples of inactive vent site. ${ }^{226} \mathrm{Ra}-{ }^{210} \mathrm{~Pb}$ and ${ }^{228} \mathrm{Ra}^{2}{ }^{28} \mathrm{Th}$ ages obtained for part of the present samples are discussed in comparison with the present ESR ages by Uchida et al. (Chap. 47).

\subsubsection{Daiyon-Yonaguni Knoll Field}

The age of active chimney (818-S-01) from an active vent site ranges from 580 to 990 years, while the samples from active vent sites (2K1267L1, 2) show younger ages, 200 and 260 years.

\subsubsection{Hatoma Knoll Field}

The ESR ages of inactive chimney (HPD\#1331G01) were 2,400-3,700 years, which are statistically indistinguishable. ${ }^{210} \mathrm{~Pb}$ in this sample was in radioactive equilibrium with ${ }^{226} \mathrm{Ra}$. One piece from sulfide mound sample, HPD\#1331G03, shows an age of 990 years, which was statistically younger than other two ages of 3,000 and 
5,700 years. The age of 2K1353R2 was determined to be 970 years. The age of HPD\#1331G07 taken from an active chimney was determined to be of 7.1 years. U-Th ages were determined for sulfide minerals extracted from three pieces of HPD\#1331G01, but they vary much more than ESR ages.

Table 29.2 The dose rate conversion factors in $\mathrm{mGy} / \mathrm{y}$ calculated, summing up the energy contributions of the nuclei in the chains listed in Guérin et al. (2011), the dose rate conversion factors for ${ }^{226} \mathrm{Ra}$ and ${ }^{228} \mathrm{Ra}$ were calculated so that the dose rate can be obtained in the case of radiative disequilibrium

\begin{tabular}{|c|c|c|c|}
\hline $\mathrm{mGy} / \mathrm{y}$ & $\mathrm{D}_{\alpha}$ & $\mathrm{D}_{\beta}$ & $\mathrm{D}_{\gamma}$ \\
\hline \multicolumn{4}{|l|}{${ }^{226} \mathrm{Ra}^{210} \mathrm{Tl}$} \\
\hline per $1 \mathrm{~Bq} / \mathrm{g}$ of ${ }^{226} \mathrm{Ra}$ & 120.9 & 4.789 & 8.703 \\
\hline per $1 \mathrm{ppm}$ of virtually equilibrated ${ }^{238} \mathrm{U}$ & 1.505 & 0.0596 & 0.1083 \\
\hline \multicolumn{4}{|l|}{${ }^{210} \mathrm{~Pb}-{ }^{206} \mathrm{~Pb}$} \\
\hline per $1 \mathrm{~Bq} / \mathrm{g}$ of ${ }^{226} \mathrm{Ra}$ & 26.76 & 2.138 & 0.0241 \\
\hline per $1 \mathrm{ppm}$ of virtually equilibrated ${ }^{238} \mathrm{U}$ & 0.333 & 0.0266 & 0.0003 \\
\hline \multicolumn{4}{|l|}{${ }^{228} \mathrm{Ra}^{228} \mathrm{Ac}$} \\
\hline per $1 \mathrm{~Bq} / \mathrm{g}$ of ${ }^{228} \mathrm{Ra}$ & 0 & 2.177 & 4.353 \\
\hline per $1 \mathrm{ppm}$ of virtually equilibrated ${ }^{232} \mathrm{Th}$ & 0 & 0.0088 & 0.0176 \\
\hline \multicolumn{4}{|l|}{${ }^{228} \mathrm{Th}-{ }^{208} \mathrm{~Pb}$} \\
\hline per $1 \mathrm{~Bq} / \mathrm{g}$ of ${ }^{228} \mathrm{Ra}$ & 162.1 & 4.600 & 7.470 \\
\hline per $1 \mathrm{ppm}$ of virtually equilibrated ${ }^{232} \mathrm{Th}$ & 0.6554 & 0.0186 & 0.0302 \\
\hline
\end{tabular}

\subsubsection{Iheya North Knoll Field}

A sample from an inactive chimney (HPD\#1358R3) shows ages from 3,000 to 4,300 years, while the other sample taken from a sulfide mound (HPD\#1358R2) shows younger age 560-1,000 years, which are also statistically indistinguishable.

\subsubsection{Izena Hole Field}

Two samples from an inactive chimney (HPD\#1329G01, G03) show ages over 10,000 years. On the other hand, a sample from an active chimney (HPD\#1313G05) shows statistically consistent ages from 12 to 16 years, in which ${ }^{228} \mathrm{Ra}$ was also detected. ${ }^{228} \mathrm{Th}$ was equilibrated with ${ }^{228} \mathrm{Ra}$.

\subsubsection{Yoron Hole Field}

The samples analyzed in the present study were all from active chimneys. Older ages over 70 years were determined for HPD\#1333G05 and G06 in which no ${ }^{228} \mathrm{Ra}$ was detected while younger ages up to 56 years were determined for HPD\#1333G03, G07, G08 and for HPD\#1333G11 in
Fig. 29.4 A typical ESR spectrum in hydrothermal barite (natural sample of HPD\#1331G01d)

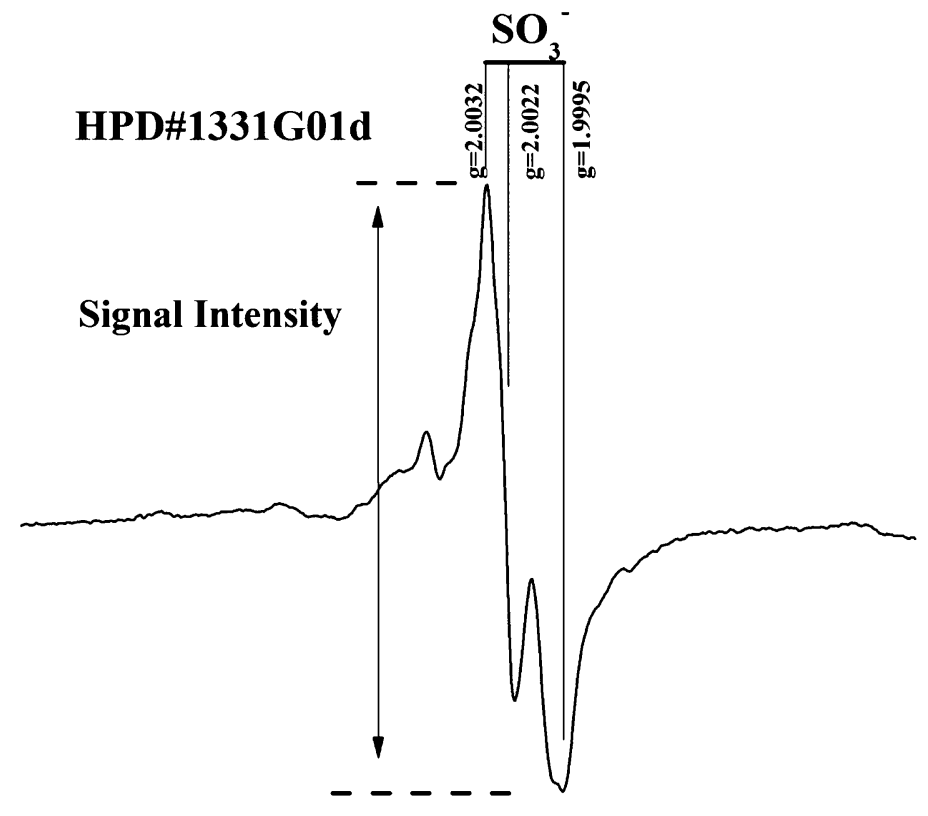

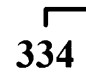

334
336 338

Magnetic Field (mT) 


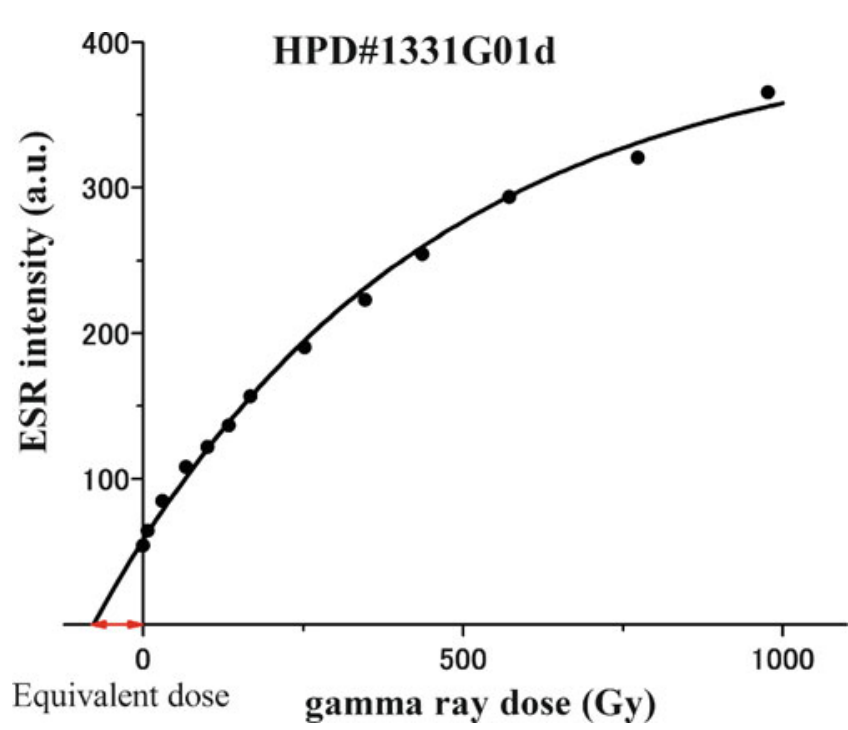

Fig. 29.5 A typical dose response of the $\mathrm{SO}_{3}{ }^{-}$signal on gamma ray dose (HPD\#1331G01d)

which ${ }^{228} \mathrm{Ra}$ was detected. The two consistent ages of 400 years were determined from two pieces of the sample, HPD\#1333G05, however, the age of 200 years from one piece is significantly younger than these ages. Another age of 330 years between these ages was also determined. It seems that there are two distinct ages of 70-80 and 120-150 years in HPD\#1333G06, which are statistically distinct. U-Th ages for this sample were less than 20 or 80 years, younger than ESR ages. ${ }^{226} \mathrm{Ra}-{ }^{210} \mathrm{~Pb}$ ages were determined for these two samples using the same barite samples for ESR measurements. The ages were 71-77 years for HPD\#1333G05 and 23-27 years for HPD\#1333G06, significantly younger than ESR ages, but the relative order is consistent. The ESR ages of 200-400 years for HPD\#1333G05 are older than 70-150 years for HPD\#1333G06, while ${ }^{226} \mathrm{Ra}^{2}{ }^{210} \mathrm{~Pb}$ ages for HPD\#1333G05 are 71-77 years, older than 23-27 years for HPD\#1333G06 (Uchida et al. Chap. 47).

The sample HPD\#1333G03 shows consistent ESR ages of 4.1-5.2 years, while ${ }^{228} \mathrm{Ra}^{2}{ }^{228} \mathrm{Th}$ ages were $4.5-5.2$ years, being coincided with ESR ages. Three ESR ages of HPD\#1333G07 were in agreement between 50 and 56 years while one piece shows significantly younger age of 28 years. ${ }^{228} \mathrm{Th}$ was in radioactive equilibrium with ${ }^{228} \mathrm{Ra}$ in these samples, which is consistent with the results that ESR ages are older than HPD\#1333G03, in which ${ }^{228} \mathrm{Ra}$ and ${ }^{228} \mathrm{Th}$ are in disequilibrium. Two ESR ages, 35 and 39 years, of HPD\#1333G08 are statistically consistent but one age of 27 years is younger, for which ${ }^{228} \mathrm{Ra}^{228} \mathrm{Th}$ was determined to be 4.2 years. ${ }^{228} \mathrm{Th}$ was in radioactive equilibrium with ${ }^{228} \mathrm{Ra}$ in the former two pieces, being consistent with ESR results.

\subsubsection{ESR Ages of Hydrothermal Field in the Okinawa Trough}

Figure 29.6 shows the determined ESR ages plotted as a geographical position of longitude of the hydrothermal fields. The order of ages of the 5 hydrothermal fields would be arranged, from young to old as follows; Yoron Hole field $<$ Daiyon-Yonaguni Knoll field $<$ Hatoma Knoll field $\fallingdotseq$ Iheya North Knoll field $<$ Izena Hole field. The samples from Hakurei site showed the high variation of ESR ages, indicating possible variation in the age of the hydrothermal fields, therefore, a conclusion based on analysis of a few samples from active sites may not be appropriate. More systematic dating works are necessary in each specific hydrothermal field in order to reconstruct the history of the hydrothermal activities.

\subsubsection{ESR Dating of Hydrothermal Barite}

Our attempt is the first study to determine such a large number of ESR ages using hydrothermal barite of many sulfide breccia samples. The results indicate that ESR dating of barite would be practically useful to investigate the history of sea-floor hydrothermal systems. The technique determines the ages more promptly than using isotopes, and is especially useful in the range from 100 to 10,000 years where ${ }^{226} \mathrm{Ra}^{2}{ }^{210} \mathrm{~Pb}$ method is not applicable. The present study showed that the method reveals relative order of the ages among the samples, however, additional efforts should be needed to establish the method for absolute age determination through further comparative dating studies. Moreover, it is also necessary to investigate the relationship and between the variation in ages and the occurrence of the minerals.

Acknowledgements The work was supported by TAIGA project, Grant-in-Aid for Scientific Research on innovative Areas (20109004) funded by the Ministry of Education, Culture, Sports, Science and Technology (MEXT), partly by MEXT-Supported Program for the Strategic Research Foundation at Private Universities (2011-2015, S1101036), and also by the Inter-University Program for the Joint Use of JAEA Facilities.

Open Access This chapter is distributed under the terms of the Creative Commons Attribution Noncommercial License, which permits any noncommercial use, distribution, and reproduction in any medium, provided the original author(s) and source are credited. 


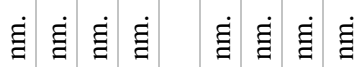

\&

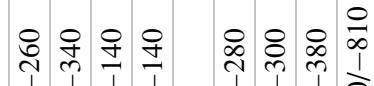

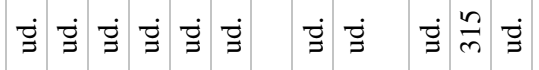

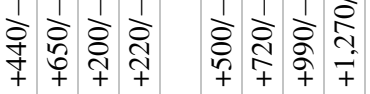

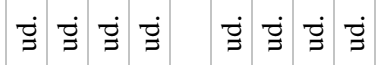

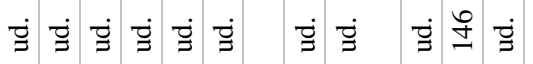

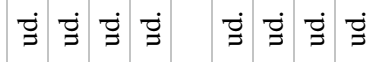
$\dot{\Xi} \Xi \dot{\Xi}$

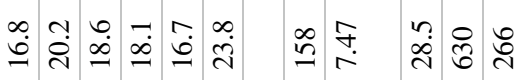
$\dot{\Xi} \dot{\Xi} \dot{g} \dot{\Xi} \dot{\Xi} \dot{\Xi}$

索学学密婇 20 さำำำ

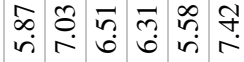

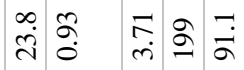
$\dot{\Xi} \ddot{\Xi} \ddot{\Xi} \dot{\Xi}$

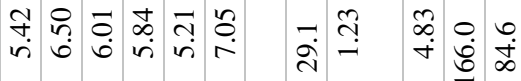

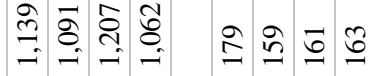
莺

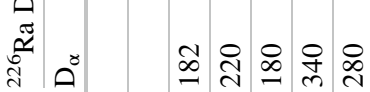

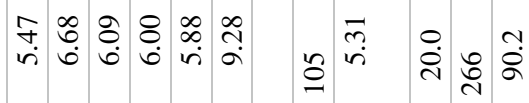

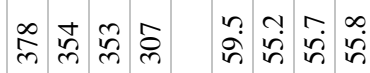

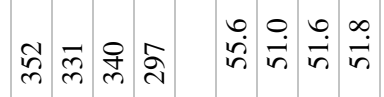

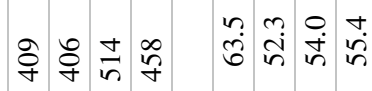

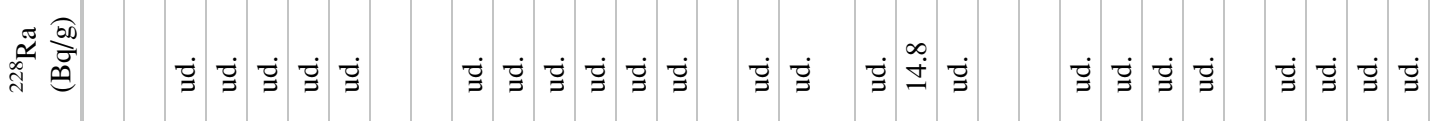
若

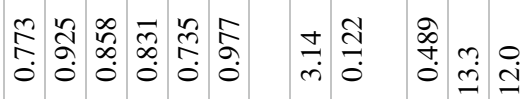

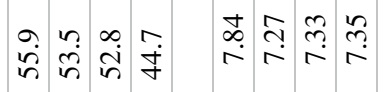

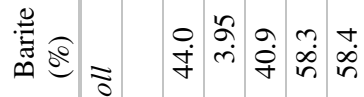

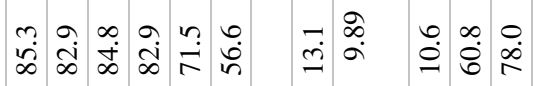

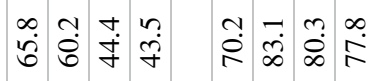

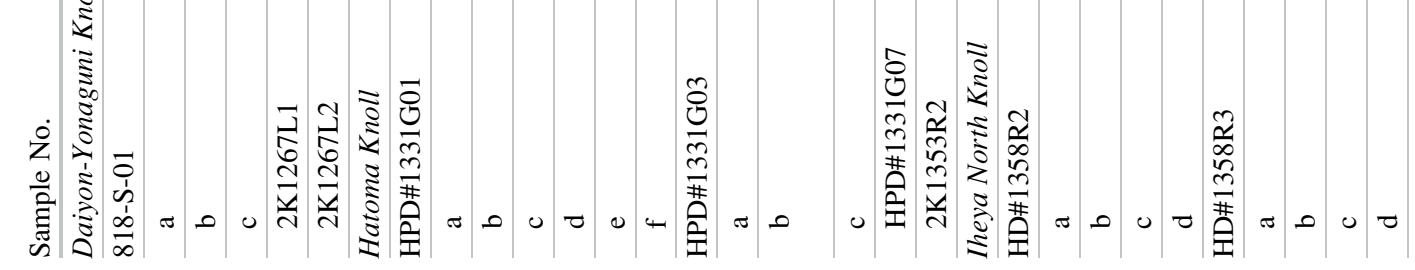




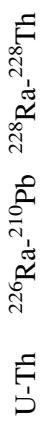

$\stackrel{m}{a} \stackrel{m}{\sim} \underset{\infty}{m}=\stackrel{\sim}{a}=$

玅

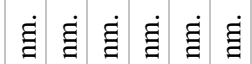

| 1

| | | | |

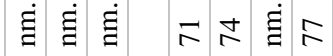

点

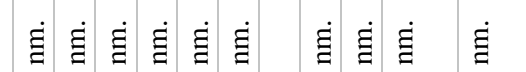

宝 宝 $\dot{\Xi} \dot{\Xi}$

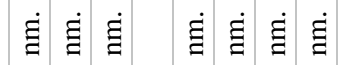

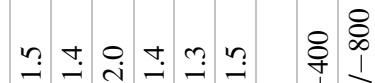

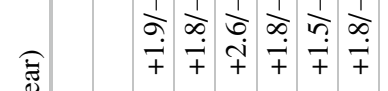

子 120

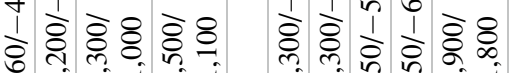

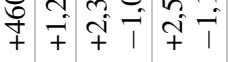

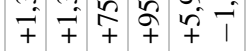

సิำ

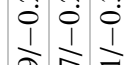

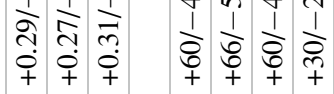

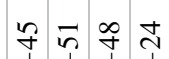

\begin{tabular}{l}
3 \\
0 \\
8 \\
\hline
\end{tabular}

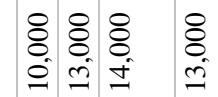

\& \& : 8

มัำำ

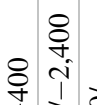

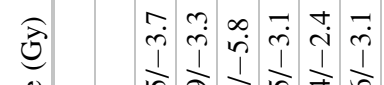

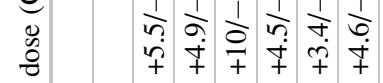

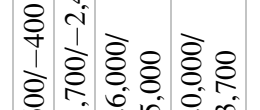

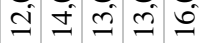

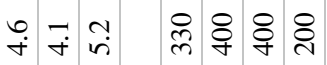

:

ลำณ

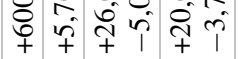

융 : $:$

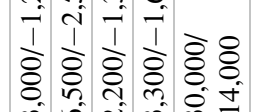

का

$\begin{array}{ccc}\infty & n & m \\ 0 & \hat{0} & \vdots \\ 0 & 1 & 1\end{array}$

$\frac{a}{\infty} \frac{1}{\infty} \hat{\sim} \pi \bar{\imath}$

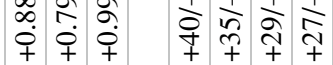

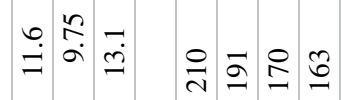

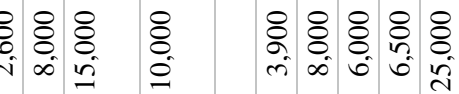

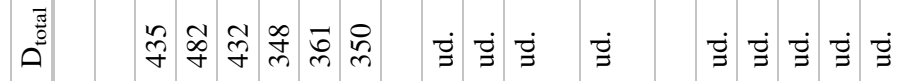

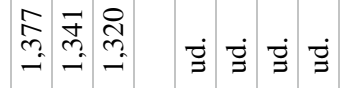

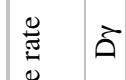

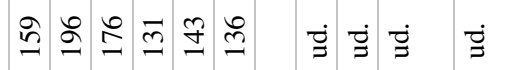

ப் $\dot{g} \dot{g} \ddot{g}$

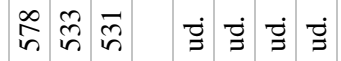

离

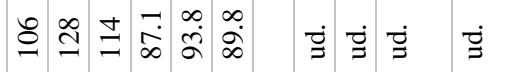

ற் ت் ت் ت்

离

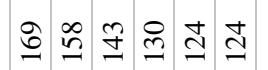

ற் ஜ் ஐ்

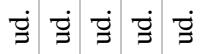

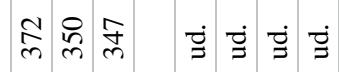

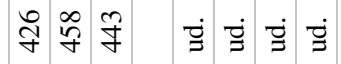

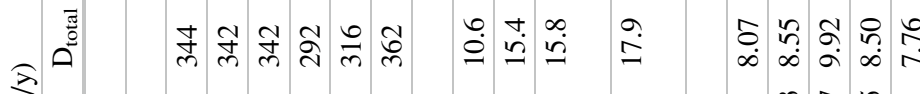

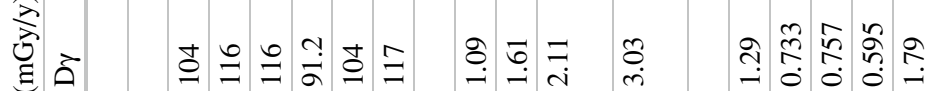

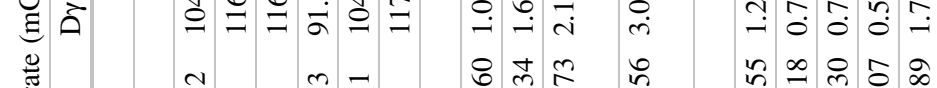

ơ

离

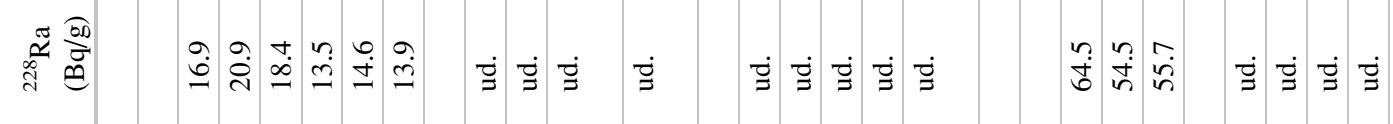

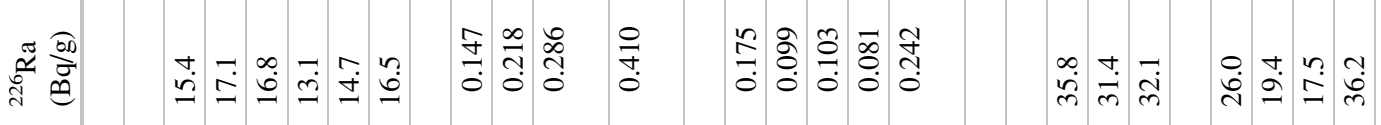

镸

r.

ఫ্ర

तี สี

సี

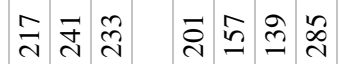
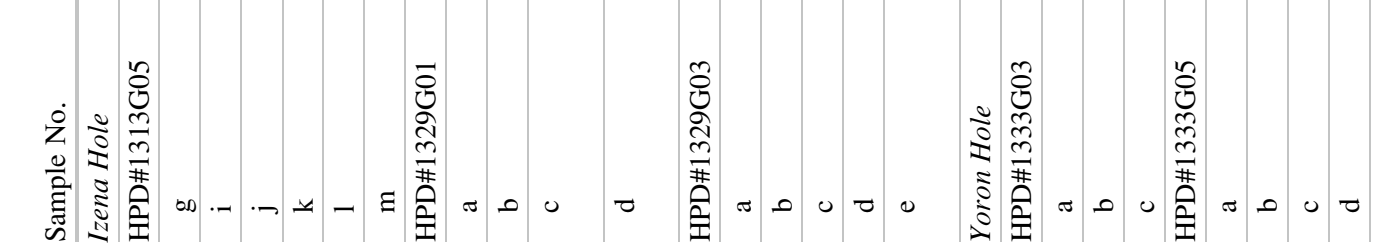


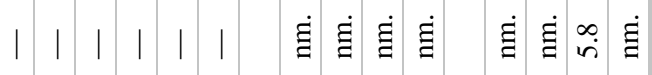

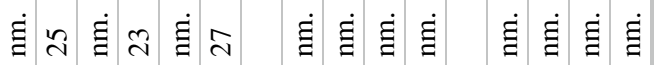

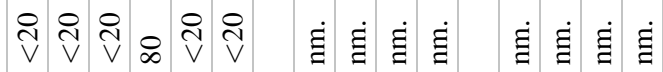

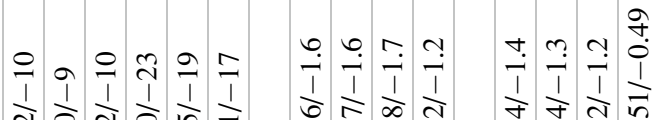

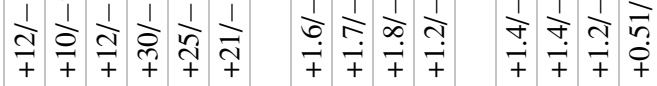

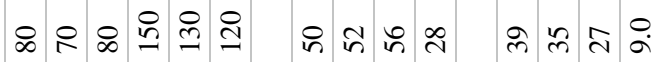

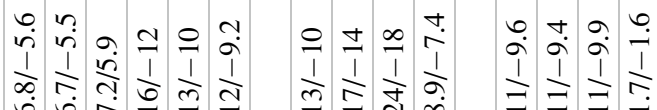

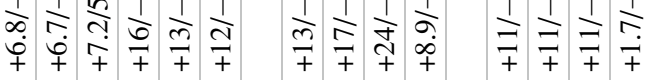

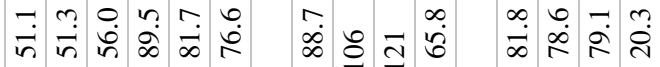

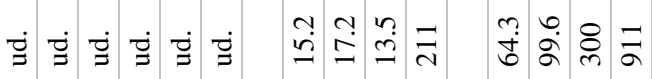

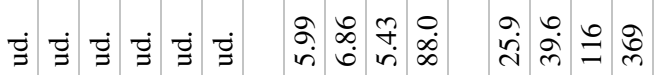

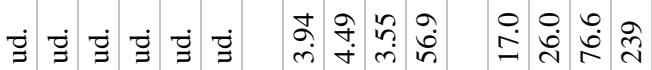

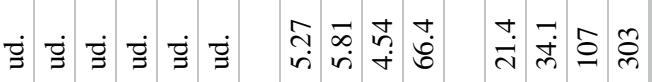

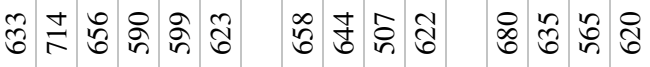

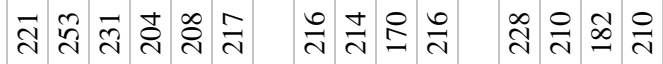

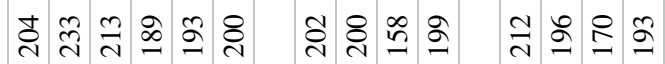
ปั่ สิ

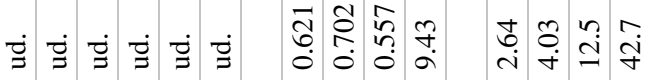

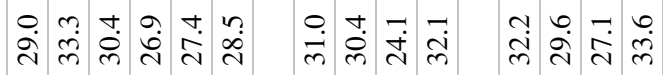

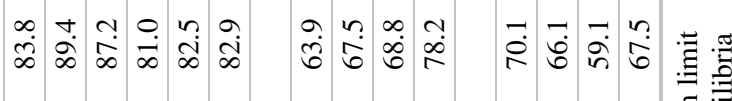

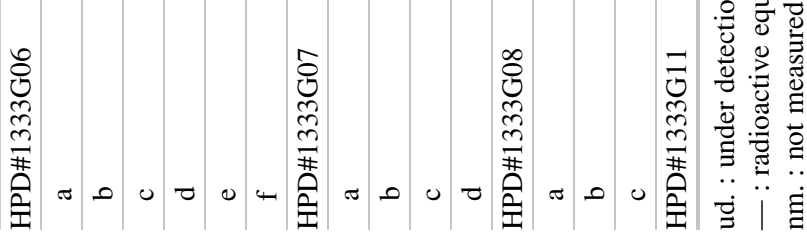


Fig. 29.6 The obtained ESR ages plotted as a function of longitude of the hydrothermal fields

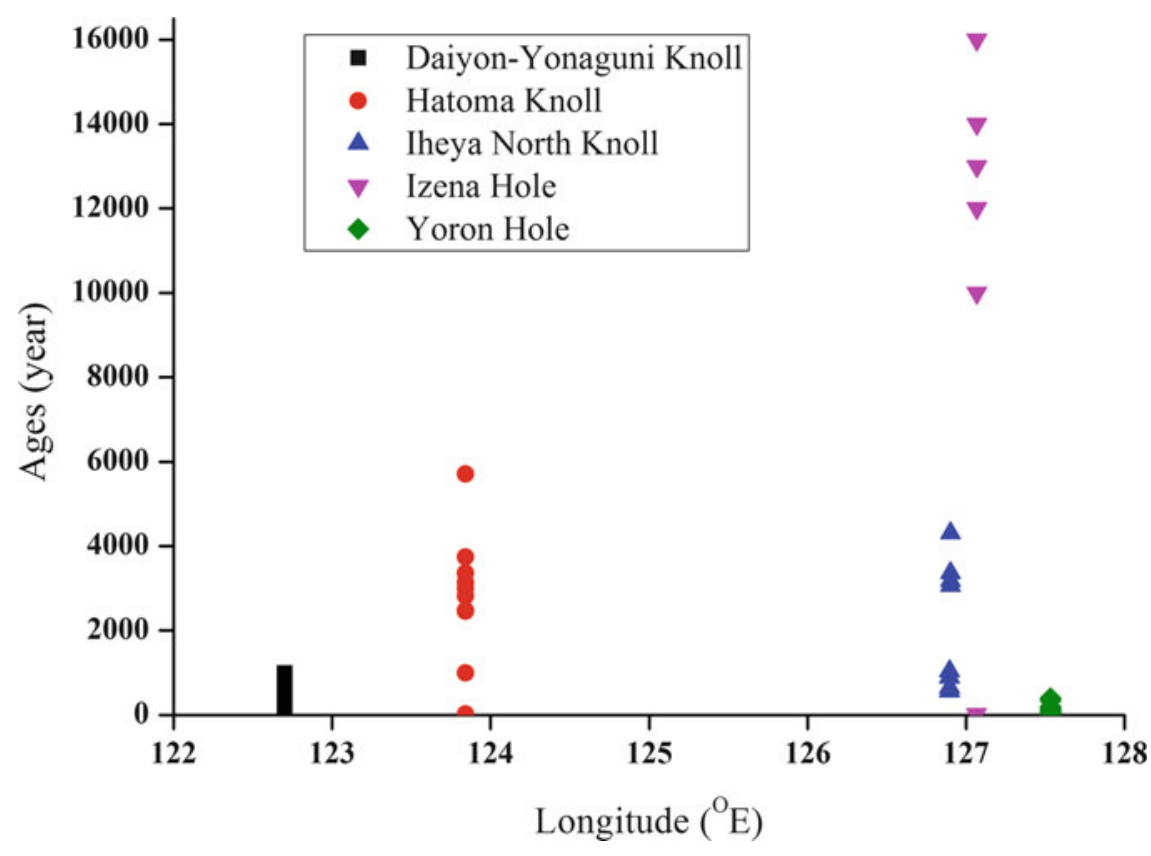

\section{References}

Guérin G, Mercier N, Adamiec G (2011) Dose-rate conversion factors: update. Ancient TL 29:5-8

Hannington MD, Jonasson IR, Herzig PM, Petersen S (1995) Physical and chemical processes of seafloor mineralization at mid-ocean ridges. In: Humphris SE et al (eds) Seafloor hydrothermal systems; physical, chemical, biological, and geological interactions. American Geophysical Union Geophysical Monograph, vol 91, pp $115-157$

Kasuya M, Kato M, Ikeya M (1991) ESR signals of natural barite $\left(\mathrm{BaSO}_{4}\right)$ crystals: possible application to geochronology. In Essay in Geology, Prof. Nakagawa Commemorative Volume: 95-98

Krystec M (1980) ESR measurements from X-ray irradiated $\mathrm{BaSO}_{4}$ single crystals. Phys Status Solidi A 57:171-178

Noguchi T, Shinjo R, Ito M, Takada J, Oomori T (2011) Barite geochemistry from hydrothermal chimneys of the Okinawa Trough: insight into chimney formation and fluid/sediment interaction. J Mineral Petrol Sci 106:26-35

Okumura T, Toyoda S, Sato F, Uchida A, Ishibashi J, Nakai S (2010) ESR dating of marine barites in chimneys deposited from hydrothermal vents. Geochronometria 37:57-61
Sato F, Toyoda S, Banerjee D, Ishibashi J (2011) Thermal stability of ESR signals in hydrothermal barites. Radiat Meas 46:866-870

Takamasa A, Nakai S, Sato F, Toyoda S, Banerjee D, Ishibashi J (2013) U-Th radioactive disequilibrium and ESR dating of a baritecontaining sulfide crust from South Mariana Trough. Quat Geochronol 15:38-46

Tivey MK (2007) Generation of seafloor hydrothermal vent fluids and associated mineral deposits. Oceanography 20:50-65

Toyoda S, Sato F, Banerjee D, Ishibashi J (2011) Characteristics of the radiation induced ESR signals in barite. Adv ESR Appl 27:4-6

Toyoda S, Sato F, Nishido H, Kayama M, Ishibashi J (2012) The alpha effectiveness of the dating ESR signal in barite. Radiat Meas 47:900-902

Toyoda S, Fujiwara T, Uchida A, Ishibashi J, Nakai S, Takamasa A (2014) ESR dating of barite in sulfide deposits formed by the sea floor hydrothermal activities. Radiat Prot Dosimetry 159:203-211

Yonezawa N, H. Matsue, Y. Miyamoto, D. Suzuki, K. Yasuda, J. Inagawa, Y. Saito (2002) Handbook for practical gamma ray spectrometry (Japanese title translated), Nikkan Kogyo, Japan. (Translation of Gilmore and Hemingway, 1995, Practical gamma-ray spectrometry, Wiley, Chichester/New York/Brisbane/Toronto/Singapore)

You CF, Bickle MJ (1998) Evolution of an active sea-floor massive sulphide deposit. Nature 394:668-671 